\title{
Systematization of Features and Recommendations Regarding Architectural and Urban Planning and Placement of University Hospitals
}

\author{
Irina Bulakh ${ }^{1, *}$, Olena Kozakova ${ }^{2}$, Margaryta Didichenko $^{1}$, Olena Chala ${ }^{2}$ \\ ${ }^{1}$ Department of Design of Architectural Environment, Faculty of Architecture, Kyiv National University of Construction and \\ Architecture, Kyiv, 03037, Ukraine \\ ${ }^{2}$ Department of Information Technologies in Architecture, Faculty of Architecture, Kyiv National University of Construction and \\ Architecture, Kyiv, 03037, Ukraine
}

Received February 10, 2021; Revised May 15, 2021; Accepted October 20, 2021

\section{Cite This Paper in the following Citation Styles}

(a): [1] Irina Bulakh, Olena Kozakova, Margaryta Didichenko, Olena Chala, "Systematization of Features and Recommendations Regarding Architectural and Urban Planning and Placement of University Hospitals," Civil Engineering and Architecture, Vol. 9, No. 7, pp. 2476 - 2491, 2021. DOI: 10.13189/cea.2021.090732.

(b): Irina Bulakh, Olena Kozakova, Margaryta Didichenko, Olena Chala (2021). Systematization of Features and Recommendations Regarding Architectural and Urban Planning and Placement of University Hospitals. Civil Engineering and Architecture, 9(7), 2476 - 2491. DOI: 10.13189/cea.2021.090732.

Copyright $\odot 2021$ by authors, all rights reserved. Authors agree that this article remains permanently open access under the terms of the Creative Commons Attribution License 4.0 International License

\begin{abstract}
The purpose of the article is to identify the architectural features of the university hospitals design, which are based on a comprehensive analysis and systematization of the existing historical and recent global perspective, as well as the study of the latest trends in the development and architectural design of medical institutions in leading countries. The University Hospital is a multifunctional medical complex that combines and synthesizes several functions: multidisciplinary and specialized, educational and training, and research functions, experimental and innovative items production, as well as various auxiliary, secondary services and processes. The main contribution and originality of the study is the systematization of the existing experience in the construction of clinical and university hospitals and on this basis, the punctuation of the main provisions, features, and a number of recommendations (architectural-planning, structural and construction materials, master plan, aesthetic and artistic solutions, and functional components of the blocks) for the architectural design of these types of medical institutions. The main and significant conclusion of the article is the understanding of the individual project approach to the design of university hospitals, as well as the need for their active development as the most promising and effective type of hospital structure. When
\end{abstract}

designing university hospitals, it is also proposed to take into account the principles of sustainable development and apply them within the boundaries of environmental design aimed at reducing the negative impact of urbanization processes.

Keywords Clinical Hospital, Clinics' Extension, Clinics' Poly Structure, Medical Design Trends

\section{Introduction}

In the vast majority of the countries the condition of development of the medical industry indicates the standard of living of society, attitude towards the health of citizens, and concern for the health of future generations. According to the WHO Copenhagen Declaration, public health is considered as the main criterion for the benefit and effectiveness of all the spheres of economic activity without exception. Nowadays, a lot of countries, including Ukraine, lag far behind the world's leading countries in a number of indicators of quality and efficiency of the healthcare systems and facilities $[1,2]$.

This phenomenon is caused by many factors, including environmental pollution, lack of gradual and timely 
architectural and urban modernization of the medical system, limited access to quality and modern health care, lack of a culture of healthy living, the prevalence of self-medication, untimely treatment, and consequence, numerous chronic diseases [3, 4]. It should be noted that health care reform is a complex, politically negative process for any country, always accompanied by criticism, protests, and opponents of change [5-7]. The only way out of this situation is to introduce step-by-step changes without abrupt and cardinal instant updates, which provide a basis for more correct adaptation and coordination. The globe has been shaken almost every year by the emergence and spreading of new epidemics and pandemics. In the context of globalization and urbanization together with the latest infectious diseases, despite the initial appearance and territorial localization, relatively briefly flare up in different and remote parts of the world, gradually unfolding and gaining destructive momentum in all countries and continents [8-10]. These new realities and threats draw our attention to how vulnerable human health and life really are.

Many leading and ambitious world powers have focused their research attention and significant resources on space exploration for decceniums. Aloof planets attempt to find signs of new life. However, there is a little attention paid to the importance of the need to preserve and protect human health on Earth [11-14]. Thus, the events of the last six months have become a warning to all countries of the world about the real and urgent threats, priorities, and objectives of the original research and practical programs aimed at ensuring the efficiency and quality of healthcare.

Trends studies in the urban and architectural development of healthcare system of the leading countries e.g., United States, UK, Germany, France, as well as studies of success factors in front-line countries in the medical area (Hong Kong, Singapore, the United Arab Emirates) revealed a number of patterns and directions of development and organization. One of the characteristics is the consolidation, poly-structural and multifunctional of the newest medical institutions [15-19].

The listed characteristics of medical institutions were most successfully realized in the university clinics. For most of these countries, this type of hospital is a leader in various government programs to ensure and innovative development of the medical sector. Therefore, the study endeavours to introduce main design features of university hospitals, which are the next evolutionary step in comparison with clinical hospitals.

This study is of great importance for countries that are reforming their health care systems. According to the authors of the article, it is university hospitals that should play a key role in the design of the urban planning hospital net of the medical care system. Based on this, the article made an attempt to provide a number of recommendations for an architectural and planning, constructive nature, and also considered the use of building and finishing materials, designing a master plan, aesthetics, and the artistic image of university hospitals.

\section{Materials and Methods}

The study and analysis of the design of the features of the architectural environment of university clinics was carried out using an integrated, functional, systemic, historical research approach. In this article, the authors used several research methods. It is worth highlighting: comparative-historical, inductive, abstract-analytical, statistical, as well as the method of conducting quantitative and qualitative analysis, accumulation, and systematization of data obtained from diversified open databases.

\section{The Situation in Former Soviet Union Countries in the Field of the Organization of Hospitals that are Similar to the University Type}

It is worth mentioning that university clinics are not that common in lots of countries around the globe. The issue of introduction of medical institutions of this type was especially acute in the post-Soviet space, where the formation of the health care system was largely completed in the '70-' 80 s of the last century and since then there have been no significant processes of renovation and modernization of architectural and urban location of medical institutions.

Nowadays, there is no territorial-spatial and functional connection between numerous medical educational institutions, hospitals, and medical centers, research institutions and establishments, industrial and experimental production of related industries in Ukraine. Of course, this approach causes numerous negative consequences complicating the practical use and consolidation of theoretical knowledge of medical students, delaying the exchange of progressive experience of practitioners, the introduction of innovative methods of diagnosis, treatment, and rehabilitation, and many other aspects. The closest type of post-Soviet medical institutions to university hospitals are clinical hospitals, where medical departments operate and where young doctors undergo internships. Examples of clinical hospitals that function today in post-Soviet countries are shown in Table 1. 
Table 1. Architectural and urban planning analysis of clinical hospitals in Ukraine, Belarus, Russia (Developed by Author)

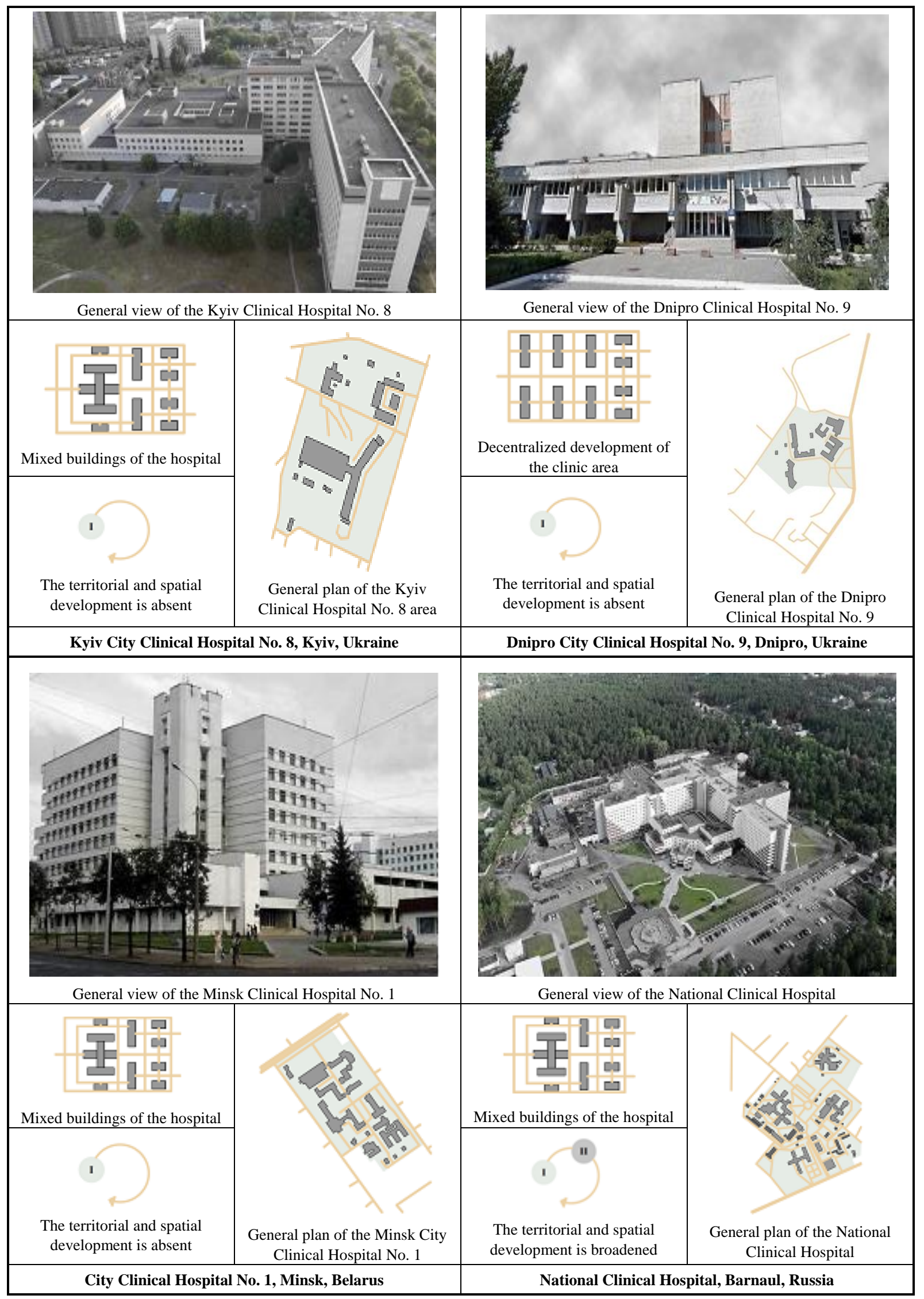


Unfortunately, in the majority of the post-Soviet countries, clinical hospitals have not received the needed expansion to create modern educational conditions and needs - there is a significant lack of auditoriums together with the rooms for students, as well as a number of other ancillary spaces. From this position, the analysis of the existing world experience of architectural design and operation of university hospitals, together with advanced trends, forms the basis for identifying the features of the architectural environment of one of the promising types of hospitals.

The Kyiv City Clinical Hospital No. 8 located in Kyiv (Ukraine) was built in the 1980s (Table 1). The hospital occupies quite a large area and hospital buildings have a mixed location. Given the rather cold climate of Ukraine, such a solution is ineffective, since it complicates the relationship between different functional department that makes it inconvenient to move patients and medical personnel. Since its construction, the hospital has not been expanded or modernized. It should also be noted that the large territory of the hospital does not have the necessary level of improvement and has not been reconstructed since the hospital was built - there is no landscape design, organized recreation areas for patients and staff, and there are not enough parking spaces. A similar situation can be observed when examining the Dnieper City Clinical Hospital No. 9, built in the same period in the city of Dnipro (Ukraine) (Table 1).

The hospital area is more compact, but all hospital buildings are decentralized. Similar problems arise for visitors and staff. This approach to the design of clinical hospitals is typical not only for Ukraine. For example, City Clinical Hospital No. 1, located in Minsk (Belarus), also occupies a significant area in the city center (Table 1). Many hospital buildings have a mixed layout and most of them are not connected to each other. Similarly, there is also a lack of further development of the hospital since its construction.

Most clinical hospitals in Russia, as well as in Ukraine and Belarus, have similar characteristics - a large area of the territory, on which there are many decentralized hospital buildings with a height of 2-6 floors. Some exceptions can be National Clinical Hospital (Barnaul, Russia), which after construction was significantly modernized and received a multi-story centralized building (Table 1).

\section{The Concept of the University Hospital and Its Place in the Urban System Structure of the Healthcare Institutions}

\subsection{Definition of a University Hospital and Its Main Tasks}

The university hospital provides a complex combination of medical, diagnostic, rehabilitation, training, research and experimental functions, combined and interacting in one multifunctional complex, located within the same territory or in different areas. University hospitals, as a rule, receive state status and are designed to serve the population of the whole country, without connection with the place of residence of the citizen. Based on these provisions, the capacity of the university hospital should be calculated at least 800-2000 inpatient beds. To expand the efficiency and productivity of the university hospital, the hospital complex should additionally include a consultative-diagnostic medical center, a powerful day hospital and a hotel for outpatients from other cities [20-22].

When conducting this research, first of all, it is necessary to understand what the main tasks should be performed by a university hospital. In our opinion, these include:

- Concentration of leading specialists of the hospital, medical-educational, research, industrial-industrial sectors in order to interact and synthesize the progressive and effective development of the medical industry, improve the capacity of the public medical care, reduce morbidity, hospital mortality, disability and mortality.

- Delivering the innovative multidisciplinary and highly specialized inpatient and consultative-diagnostic medical care for the population of the region or state.

- Arranging and conducting the educational process for students of higher and other professional educational institutions of medical profile on the theoretical and practical stages of acquiring knowledge and skills by using modern achievements of medical science and technology.

- Integration, development and implementation of advanced research and experimental research in the medical field.

- Involvement of industrial and pharmaceutical production for innovative theoretical and practical developments aimed at the emerging development of medicine.

- Formation and promotion of a new form of economic development of the country, which is based on the so-called medical tourism.

- Providing the other treatment-and-prophylactic and diagnostic institutions with consultative and organizational-methodical assistance for making the medical care system more efficiency.

- Improving the quality of training and qualification of medical personnel.

That is to say that all the global university hospitals are facilities were built according to individual projects have various functional components. It's quite difficult to discover at least two absolutely identical university hospitals in the world. Based on this, it is very hard to 
classify and compare patient / square meter - the data obtained will be very conditional and uninformative. Despite this at the end of the study a comparison has to be be done based on the data of the most famous built university hospitals in the world according to various criteria.

\subsection{The Place of the University Clinics in the Urban Planning System}

In the recent related studies, the urban planning bases of territorial and spatial development of the system of healthcare institutions, the concept of further development of the medical field in the architectural and urban planning aspect were formulated [23, 24]. The urban planning core of medical care facilities might be approached as a complex and dynamic, hierarchical and multi-layered structure that integrates medical, administrative, research, medical education, medical industry and other ancillary subsystems within a defined territory (countries, region, area, settlement or its part) [25]. The multi-layered urban planning system of healthcare institutions reflects the hierarchical structure and subordination of the components of medical levels and the corresponding urban networks of medical institutions and complexes. It is proposed that the treatment subsystem should consist of three treatment levels-networks: grids of the primary, the secondary and the tertiary medical care facilities [26, 27].

The first hierarchical step of the urban matrix of medical care institutions is a mesh of primary healthcare facilities, which provides medical care for the population on the basis of family medicine in a diversity of primary medical care facilities (basic and additional). The basic primary care facilities include: family doctors' offices, outpatient clinics, primary care medical centers. Additional places include the possibility of integrating this function into consultative and diagnostic medical centers at hospitals of the network of secondary and tertiary care facilities. This will allow one to receive medical care throughout the year and around the clock, reducing the burden on the emergency medical service in non-hospital cases. At the organization state of the secondary medical care, the care institutions network is proposed, which includes six main types of hospitals, which has different options of the care intensity, technical and personnel equipment [28].

The network of secondary care facilities includes: multidisciplinary intensive care hospitals, hospitals for planned treatment of chronic patients, rehabilitation hospitals, hospices, medical and social care hospitals, maternity hospitals, as well as counselling and diagnostic centers at these hospitals and a number of specialized medical centers (dental and others) [29]. The organization of tertiary (specialized) medical care is the responsibility of the urban network of tertiary medical care institutions, the operation of which is proposed at the national level and within hospital regions. It is at the tertiary treatment level that the organization and functioning of university hospitals as the highest and leading hospital care is proposed. The peculiarities of university hospitals include their medical multidisciplinary nature and the presence of most medical specializations, which are combined with the educational center (medical university, college and other educational medical institutions) on the basis of progressive and developed material and technical equipment, as well as laboratory, diagnostic, scientific experimental production activities.

\section{Historical Experience of the University Hospital Design}

\subsection{Analysis of Architectural and Urban Planning Solutions of the Hamburg-Eppendorf University Hospital, Hamburg, Germany}

One of the best known and largest university clinics is the Hamburg-Eppendorf University Hospital, located in Hamburg, Germany. The first building of the hospital is dated by the 1884. In 1889, the hospital complex had 70 buildings located in the city park. In the beginning of the twentieth century the German architect Fritz Schumacher built the main building of the university hospital, which today has expanded significantly and includes about 170 buildings, has a total of 1,700 hospital beds, including 1,460 hospital beds and 121-day hospitals (Table 2).

The hospital complex includes the main medical departments: Oncology Centre, Surgical Centre, Cardiology Centre, Brain and Clinical Neurosurgery Centre, Martini Clinic, Ophthalmology Centre, Centre for Internal Medicine and Dermatology, Centre for Obstetrics, Paediatric and Adolescent Medicine, Centre for Anaesthesia Centre for Dentistry and Facial Orthopaedics, Centre for Psychosocial Medicine, Outpatient Centre, which form more than 80 clinics, clinics and institutes that work together on an interdisciplinary basis. The Hamburg-Eppendorf University Hospital is an educational base for medical students at the University of Hamburg and trains around 3,300 future doctors each year.

The hospital complex also includes numerous research laboratories and institutes. Particularly one of the operations are aimed at studying new methods of treatment of paediatric oncology. The staff of the university hospital includes more than 10,000 people who treat about 95,000 inpatients and about 335,000 outpatients each year.

Despite the already achieved significant territorial and spatial scale of the University Hospital Hamburg-Eppendorf, the construction of new buildings of the complex is planned by 2050 . This university hospital is an excellent example of the development of a hospital complex in the dense development of a historic city almost the entire hospital area was built up in several 
stages. The expansion and modernization of the hospital complex was constantly carried out, new hospital buildings were built for the necessary functions (educational, medical, advisory, etc.). Most hospital buildings have warm passages, which allow patients and medical staff to move around comfortably. All new buildings of the hospital are designed in the context of the existing buildings, which makes it possible to perceive the entire complex of the university hospital as one integral architectural ensemble.

\subsection{Analysis of Architectural and Urban Planning Solutions of the University Medical Complex, Freiburg, Germany}

One of the oldest university hospitals is the German medical complex of Freiburg. The history of the hospital of the University Clinic of Freiburg, which was established on the basis of the medical faculty of the University of Freiburg named after Albert and Ludwig established in 1457 (Table 3) [30].

In 1751 medical students began to engage in charitable activities, caring for patients in the city hospital for the poor. This volunteer initiative contributed to the establishment in 1780 of the first clinical general practice hospital at the university. In the XIX century, the main medical center was opened, which consisted of various specialized units. In 1887 a psychiatric clinic was opened, and in 1926 the architect Albert Lorenz set up the erecting of a modern hospital complex on the territory of the present hospital campus. During the Second World War, during the bombing of 1944 almost all medical buildings of the university complex were destroyed, their reconstruction was started only in 1952. Since then, the university complex is constantly expanding, including an ever-widening range of component clinics.

Today the University Hospital of Freiburg is a center of innovative education, research and development of world-class medical care. The clinic has 13,100 specialists, including 1,710 doctors and 3,572 nurses. The total number of beds is 2107 beds. The University Hospital Freiburg receives about 91,000 inpatients and 872,000 outpatients per year.

The treatment units of the university hospital include the following profiles: anaesthesiology and intensive care, gastroenterology and hepatology, gynaecology, dermatology, paediatric and adolescent medicine, paediatric cardiology, general paediatrics, neuropaediatrics and muscle diseases, paediatric oncology and haematology-vascular surgery, cardiology and angiology, paediatric cardiology and congenital heart disease.

Table 2. Architectural and urban planning analysis of the University Hospital Hamburg-Eppendorf, Hamburg, Germany (Developed by Author)

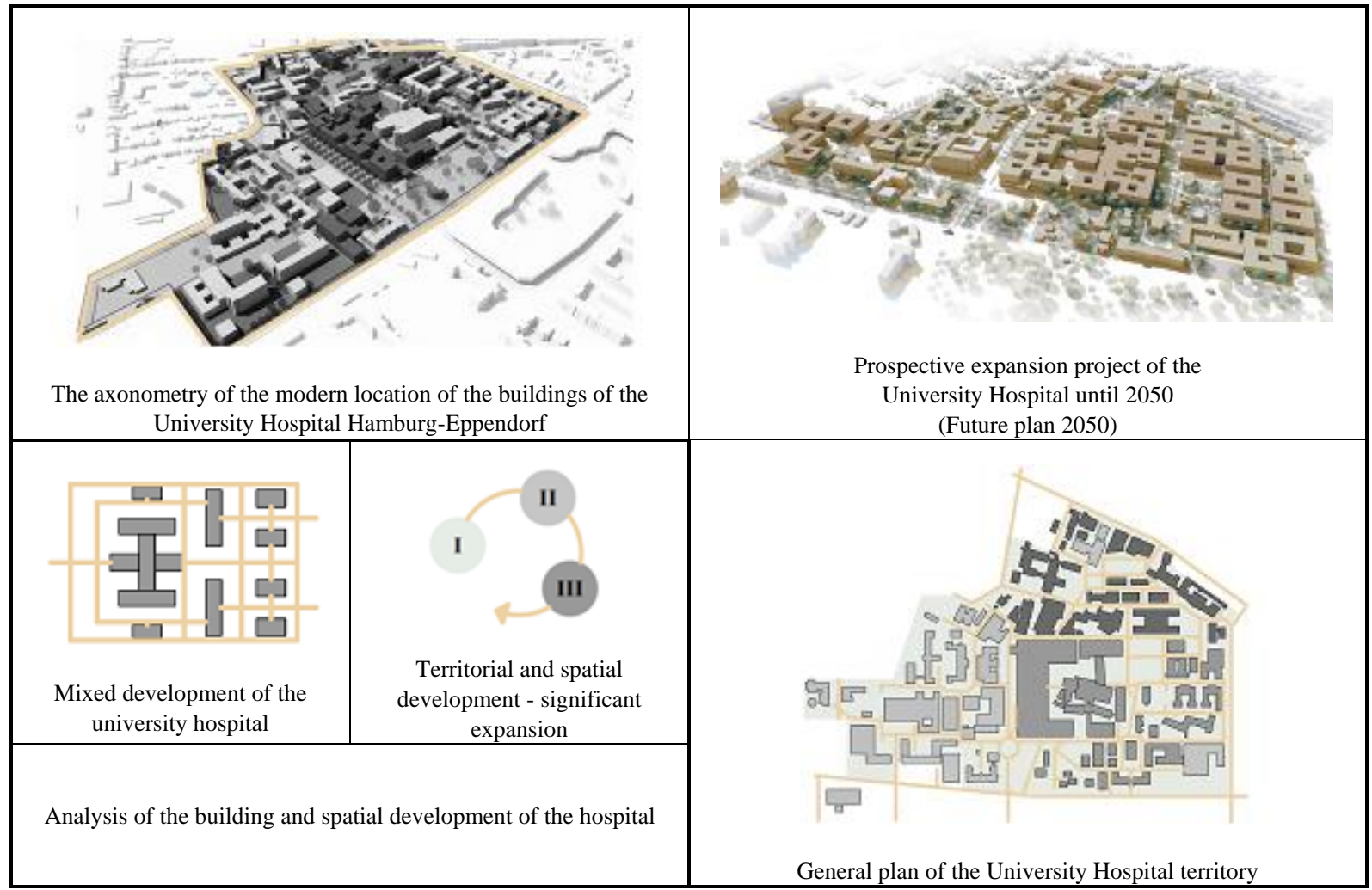


Table 3. Architectural and urban planning analysis of the University medical complex, Freiburg, Germany (Developed by Author).

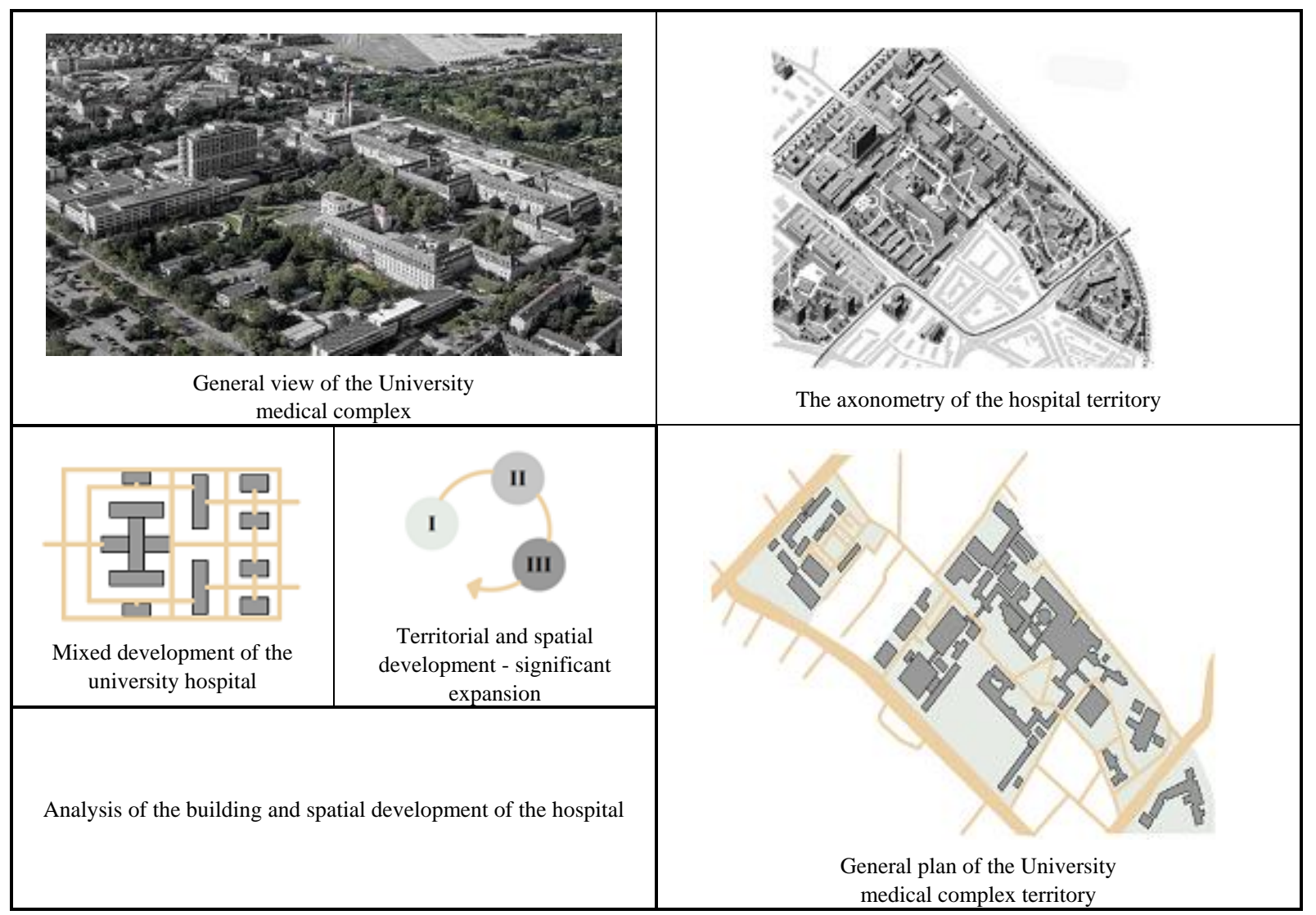

The hospital also has: otorhinolaryngology, radiation therapy, neurocentre, neurology and neurophysiology, general neurosurgery, stereotactic neurosurgery, epileptic center, neuropsychology, neuroradiology oncology and haematology, orthopaedics and traumatology, ophthalmology, plastic and hand surgery, psychotherapy, psychiatry and pulmonology, rheumatology, radiology, dentistry, clinical immunology, operative dentistry, maxillofacial surgery, orthodontics, periodontology, periodontology, prosthetics, urology, thoracic surgery, nuclear medicine and endocrinology. In addition, the university hospital has a number of institutes and interdisciplinary centers, including: Institute of Human Genetics, Institute of Industrial Medicine \& Musculoskeletal Health, Institute of Clinical Chemistry, Centre for Lipid Metabolism, Institute of Music Therapy, Institute of Pathology, Institute of Tumor Prevention, Institute of Forensic Medicine, Institute of Cellular and Gene Therapy, Centre for Transfusion Medicine, Institute for Prevention of Infectious Diseases and Clinical Hygiene, Centre for Geriatrics and Gerontology, Centre for Complementary Medicine, Centre for Continence, Centre for Breast Cancer Treatment, Centre for Rare Diseases, Centre for Rare Diseases, Centre for Medical Microbiology and Hygiene, Centre for Sleep Medicine, Centre for Muscle Diseases, Emergency Centre, Oncology Centre, Transplant Centre, Central Physiotherapy, Centre for Chronic Immunodeficiency, which are designed for research and development of innovative treatments for these groups of diseases [30].

This university hospital serves as an excellent example of the evolutionary development of architectural and urban planning solutions of hospital complexes, which, in the process of their expansion and modernization, allowed reaching a balance in the rational use of the territory and at the same time allowed preserving the landscape park, courtyards and a sense of free space. If further modernization of this university hospital is required, it is recommended that a hospital building with a higher number of floors instead of several low-floors buildings to be designed. Such a solution will allow preserving the landscape park on the territory of the hospital and at the same time creating the necessary areas to accommodate new functions. Also, a high-rise building allows creating more comfortable conditions for the movement of patients and medical personnel.

\subsection{Analysis of Architectural and Urban Planning Solutions of the Johannes Gutenberg University Medical Centre, Mainz, Germany}

Another example of the university hospital complex is the Johannes Gutenberg University Medical Centre in Mainz, Germany founded in 1914 (Table 4) [31]. The University Medical Centre Mainz is located in the center of Mainz, a major city in the metropolitan Rhine-Main 
Region, half an hour away from Frankfurt Airport. The construction of the university hospital was completed in 1952. Nowadays the university hospital complex covers more than 60 clinics, institutes, departments and divisions. The hospital has 7,980 employees. Every year the number of outpatients is about 300,000 and inpatient care (full and semi-hospital) - 70,000. The University Medical Centre Mainz operates over 1,500 hospital beds. A bit more than 2,900 nurses and 1,200 doctors take care of the general wellbeing of patients, their health and recovery. In addition, more than 600 students study various medical professions (nurses, speech therapists, nutritionists, obstetricians, etc.) in eight educational institutions and schools. Research work is carried out in 45 different institutes at the university hospital [31]. Thus, the medical departments of the university hospital not only provide treatment, but are also leading research items with a well-established medical education institution.

From an architectural point of view, this university hospital demonstrates a careful approach to the historic hospital complex, which was periodically expanded and modernized, but at the same time retained the integrity of a single solution to the architectural ensemble. The territory of the hospital has large parameters, but hospital buildings are grouped by functional purpose and mostly have warm passages. Thus, despite the low-rise buildings of the hospital buildings, the architects managed to achieve a balance between functional comfort and the preservation of the historical appearance of the university hospital. The design experience of this university hospital must be taken into account when expanding and renovating hospitals in historic city zones. Despite the rather dense development of the hospital territory, in the process of further design and construction of new hospital buildings, the architects were able to preserve the central hospital park, as well as small inner courtyards to provide a beautiful view from the wards for patients.

\section{The State-of-the-Art Global Experience and Trends in the Architectural Design of the University Hospitals}

Recently, one can observe a significant growth of the number and throughput of university hospitals, which are becoming a new center for the development of medicine at the state level. Gradually, there was a transition from decentralized construction of hospitals to a combined and centralized approach to the design of the medical complex. There is a rejection of the typical design of hospitals, which, of course, allows getting unique architectural objects, designed taking into account regional capabilities and needs, as well as high aesthetic quality. Today, the architecture of healthcare facilities is gradually losing the features of the "architectural shell" for the technical organization of therapeutic processes and itself acquires certain therapeutic properties [32]. One of the important directions is also the use of an ecological approach in the creation of medical institutions, which creates the basis for the sustainable development of architecture in the field of healthcare [33, 34].

Table 4. Architectural and urban planning analysis of the Johannes Gutenberg University Medical Centre, Mainz, Germany (Developed by Author)

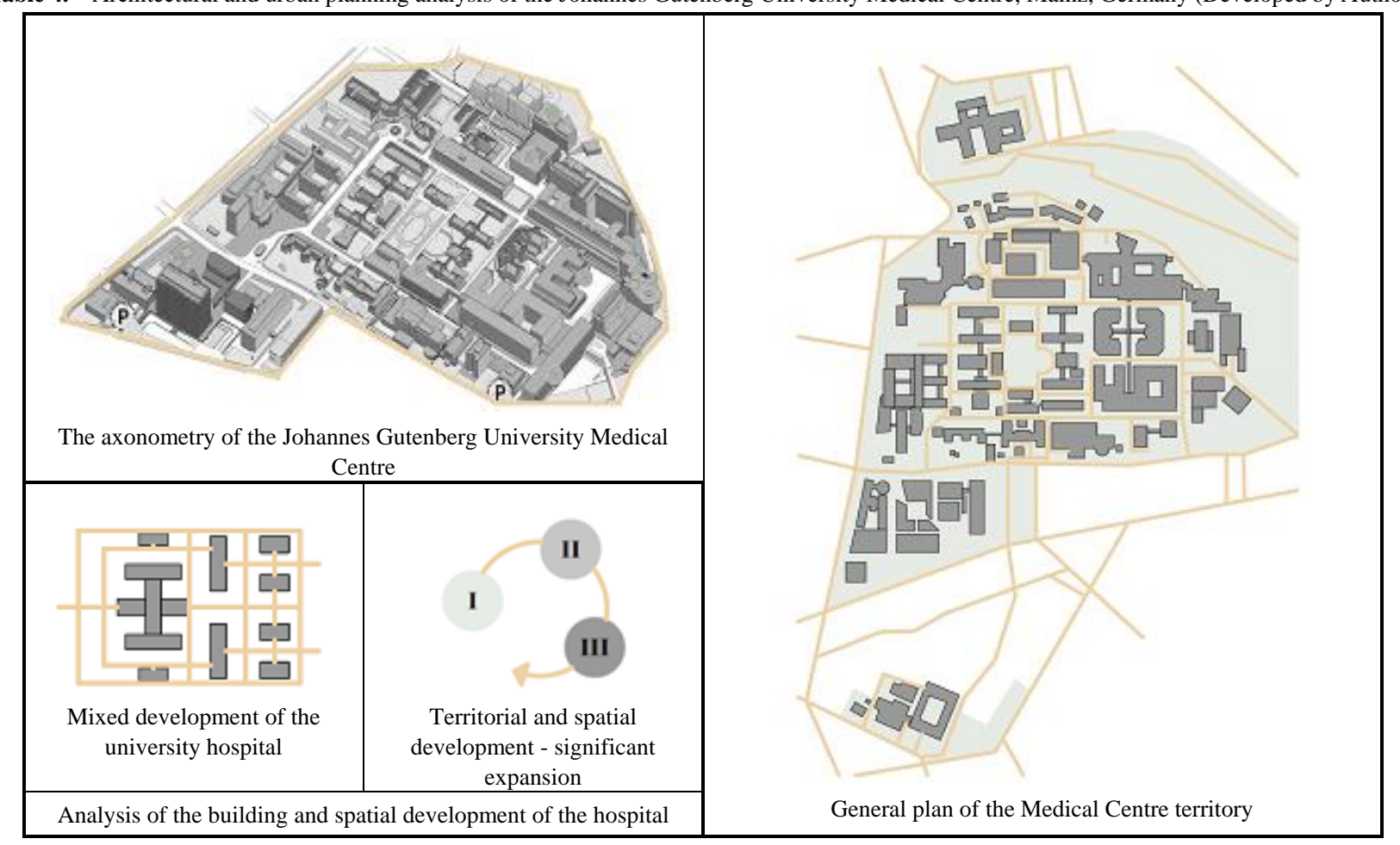




\subsection{Analysis of Architectural and Urban Planning Solutions of the Queen Elizabeth University Hospital, Glasgow, Scotland}

The new university hospital is the Queen Elizabeth University Hospital (QEUH), which was built in 2015 in Glasgow, Scotland and remains one of the largest hospital complexes in Europe (Table 5). While working on a large-scale hospital project with a total area of $175,000 \mathrm{~m}^{2}$ architects from IBI Group actively used the modern potential of information modelling (BIM technology), which allowed getting significant energy efficiency, results in the construction and further operation of the university complex. The capacity of the university hospital is designed for 1677 inpatient beds, of which 1099 belong to the adult hospital, 256 - to the children's hospital, 322 beds are located in the adult and children's emergency departments. In addition, the university hospital includes a specialized department for minors, a maternity ward, the Institute of Neurological Sciences, a ward for the treatment of the elderly, and a powerful diagnostic laboratory.

Thanks to the centralized architectural and planning solution of the hospital building, all components of the department have internal interconnections with each other, with diagnostic rooms, as well as provided with quick access to the roof with a helipad [35]. The building of the hospital for adults, 60-meters high, has 14-floors, which have four "wings" in the plan. Each room has a beautiful view from the window, equipped with a private bathroom with shower, modern media equipment. On the ground floor there is a modern public space, which changes the traditional approach to the design of hospitals, bringing it closer to the methods of organizing multi-story hotels.

In particular, the public space of Queen Elizabeth University Hospital, successfully emphasized by the atrium, includes a restaurant with 500 seats, cafes, cafes, shops, banking services. For the convenience of patients in the hospital there are special mobile lifts that effectively simplify the movement of sick people [32].

\subsection{University of Montreal Hospital Centre, Montreal, Canada}

Another significant example is the project of the new medical University of Montreal Hospital Centre (CHUM) which is one of the largest health care facilities in the world (Table 6). Construction of the university hospital began in Montreal, Canada in 1999, but due to a number of political circumstances the project was suspended and only now is nearing completion the last phase of construction of the complex. CannonDesign and NEUF architects expended almost 10 years for the design the medical megacomplex, which is a high-tech center for patient care, teaching and research.

Table 5. Architectural and urban planning analysis of the Queen Elizabeth University Hospital, Glasgow, Scotland (Developed by Author)

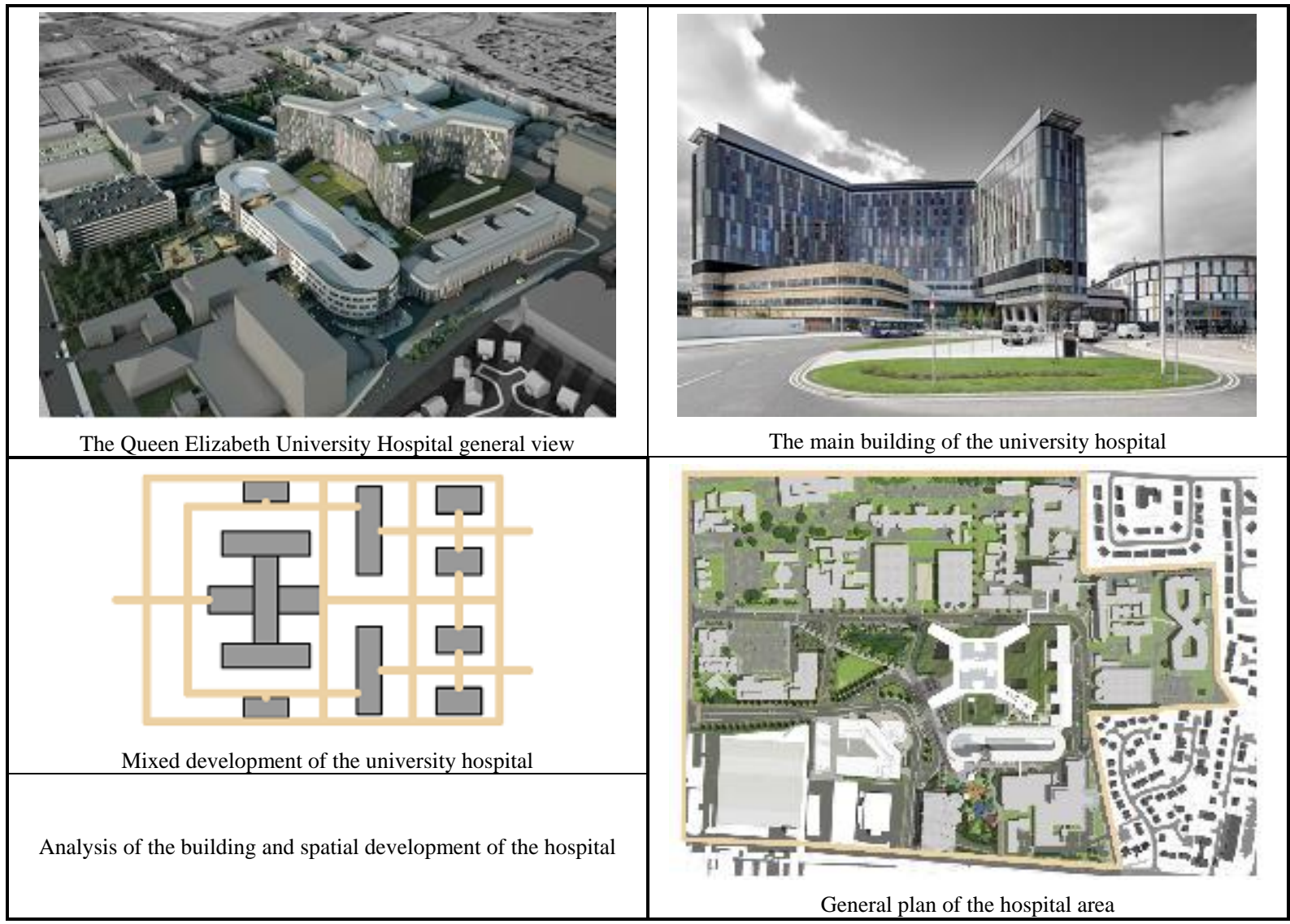


Table 6. Architectural and urban planning analysis of the University of Montreal Hospital Centre, Montreal, Canada (Developed by Author)

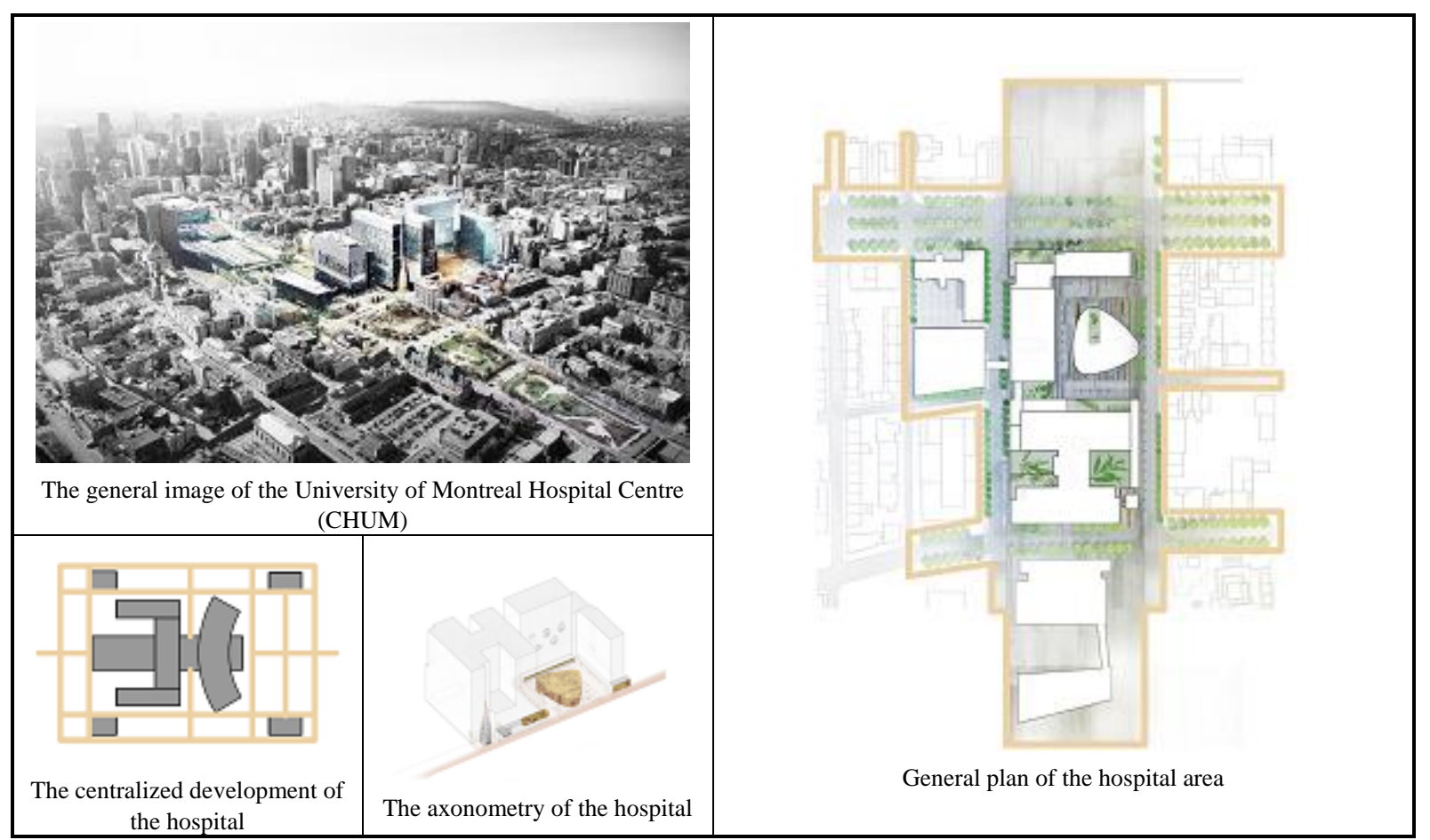

The total area of the 22-storey complex of the university hospital is about $280,000 \mathrm{~m}^{2}$ and combines three hospitals in one (Hotel-Dieu de Montreal, Hospital Notre-Dame and Hospital Saint-Luc), which has 1259 inpatient beds. University hospital staff includes 880 physicians, 330 managers, 1,300 researchers and educators, 2,370 nurses and 1,460 technicians, 3,990 other staff, and 530 volunteers [36]. CHUM University Hospital has 772 individual wards, intensive care units and 39 rooms for operating, including specialized rooms for heart surgery, robotic surgery, transplantation and neurosurgery.

New design solutions have created an integrated network of motorized vehicles for transporting equipment around the hospital, as well as about $9 \mathrm{~km}$ of pneumatic tubes for efficient and fast delivery of blood samples, various drugs, and other medical devices. When designing the CHUM University Hospital, much attention was paid to the environmental sustainability of the building - the complex consists of several environmentally friendly components, such as, for example, efficient plumbing, with the help of which it is possible to reduce the consumption of fresh water by $30 \%$ compared to a conventional standard building, as well as an individual design of ventilation and air conditioning, thanks to which the possibility of supplying $100 \%$ of fresh water enters the all wards of the hospital. The usage of the optimized heat recovery, as well as a special approach to lighting and ventilation design, maximum illumination with sunlight, architects and engineers have reduced their clean energy consumption by $50 \%$ compared to other buildings in the same climate.

\subsection{Køge University Hospital, Koge, Denmark}

Another fresh example of a university hospital is the project of a hospital in the city of Koge - Køge University Hospital (USK), located near Copenhagen (Table 7). The architects of the hospital project were C.F. Møller Architects with CUBO and Gehl Architects. Completion of the hospital with a total area of $180,000 \mathrm{~m}^{2}$ is planned in 2023 and the newest medical institution will serve about 280,000 residents of the surrounding area. It is assumed that all specialized treatment in Zealand will be provided in this medical complex, which will also serve as a center for research and educational activities in the field of health.

The hospital project envisages a centralized building of the complex in order to reduce the corridors and the corresponding load on the staff. Also, this project approach will allow to expand the hospital in perspective by adding new buildings in all directions. Much attention of architects was focused on the landscape of the university hospital with the creation of green roofs, gardens in the courtyards, which allowed to get a lot of daylight.

\section{Discussion}

\subsection{The Main Features of the Architectural Design of University Hospitals}

According to the analysis, the optimal total area of the university hospital varies in the range of 150,000-300,000 
$\mathrm{m} 2$ and depends on the number of components of interdisciplinary functions (medical, diagnostic, advisory, rehabilitation, training, research, experimental and production), as well as related ancillary appointments. It is expedient to design a university hospital in the form of a combined three-dimensional architectural space, united by a volume in which the main diagnostic, administrative and auxiliary services are located (consultative-diagnostic medical center, public catering premises, etc.). The technology of medical processes of the university hospital is focused on the combination of inpatient and outpatient (day hospital, "one-day surgery") stay of patients. In order to effectively use the hospital, as well as to provide living conditions for patients and their accompanying persons from other cities who need examination or the incidence of which provides only a day hospital, it is proposed to arrange a hotel block for 100-300 people.

Meanwhile designing a university hospital, it's worth paying attention to the introduction of the ergonomic conditions for movement, treatment and living of people with temporarily lost or permanent disabilities (ramps, elevators, automatic mobility systems, doorway sizes, corridor width, size and arrangement of toilets and toilets and sanitary facilities). The hospital should be designed on a modern world basis, taking into account the ergonomic and spatial planning features of the premises designed for the movement of people in wheelchairs, on crutches, etc.

\subsection{Architecture-Planning Aspects}

The university hospital is used all year round and is designed with the required estimated number of entrance vestibules and wardrobes (for patients, medical and technical staff). The order and distribution of human flows should provide for the delimitation: by separate functional areas of the university hospital (medical, educational, diagnostic, scientific, experimental-production, hotel, etc.); for patients (infectious, emergency, self-treatment, diagnosis, day hospital, etc.), medical (doctors, nurses, etc.) and support staff; to provide convenient communication of an entrance node and a vestibule, zones of waiting and rest, accurate and convenient orientation of patients in space, convenience and ease of vertical movement. The design of the building should take into account the physical and psychological capabilities and needs of sick patients and people with disabilities. The stage of searching for the best architectural and planning solution of the university hospital should be preceded by the stage of functional zoning with the generalized distribution of separate zones: medical, educational, scientific, diagnostic, experimental-production, hotel, etc.

Table 7. Architectural and urban planning analysis of the Køge University Hospital, Koge, Denmark (Developed by Author)

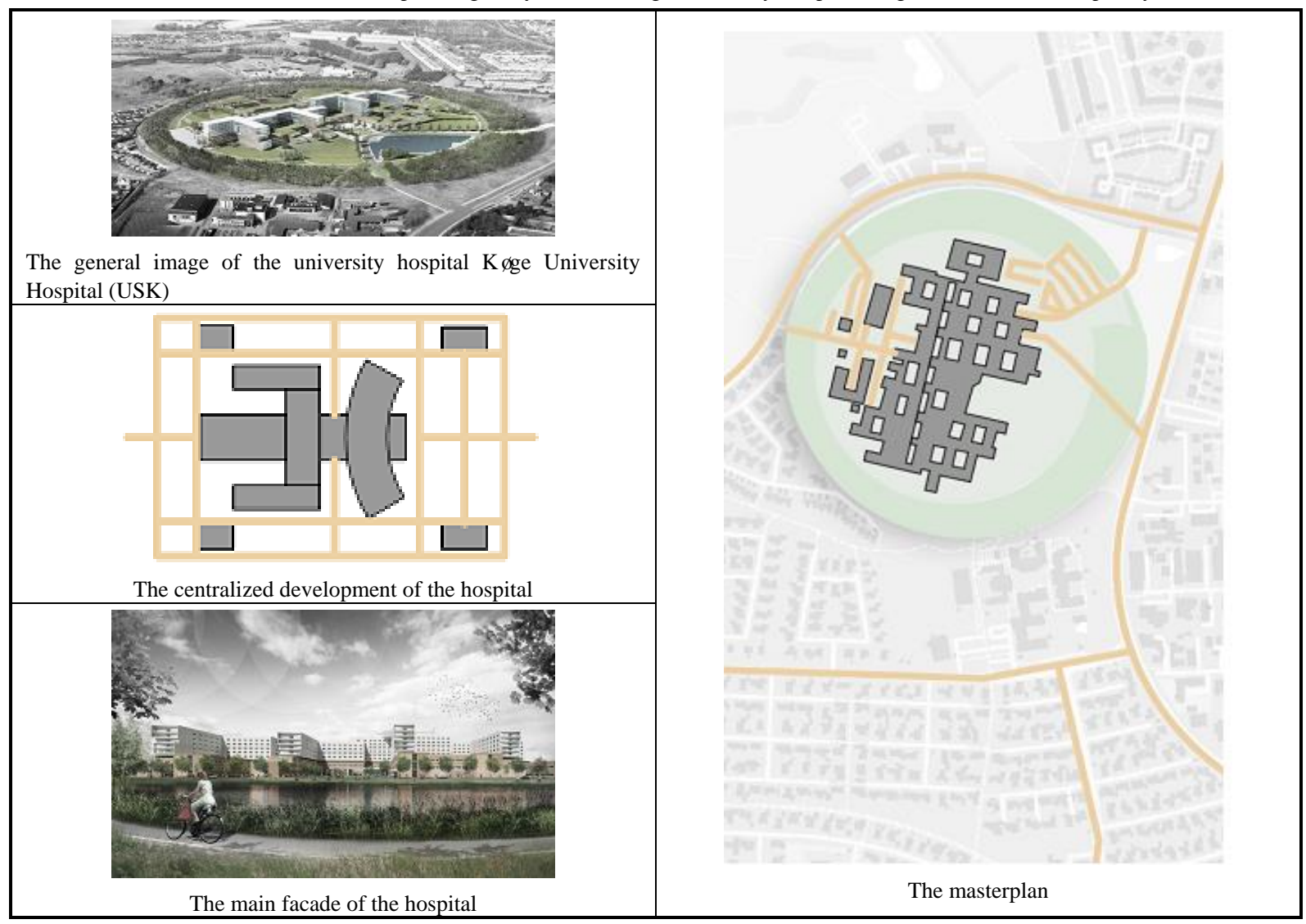


The specified list can be changed and supplemented in coordination with the customer of the project. At this stage, it is important to identify the need for interconnections of each of the functional groups of premises, as well as the number, functions and locations of their unifying blocks of premises (public space, catering and service facilities, medical center, diagnostic department and laboratory, administration, etc.). After the generalized functional zoning it is expedient to carry out internal distribution on separate components of function of each of the accepted blocks. For example, the treatment unit: entrance groups, components of departments, operating rooms with additional rooms, wards of the hospital and day hospital, internships, elevators, stairs, bathrooms, technical rooms, etc. The number of storeys of the university hospital or its individual volumes depends on the urban context and environment and the size of the selected area for development (historical or peripheral area of the city). The height of the floors is recommended to be at least $3.3 \mathrm{~m}$ and depends on the functional purpose of the premises.

\subsection{Constructions and Finishing Materials}

In the building of the university hospital, it is conditionally possible to allocate four parts which can differ in constructive decisions:

- volumes of hall spaces of educational premises (educational and lecture auditoriums);

- the volume of the hall space of the conference hall of scientific premises;

- volumes of small rooms of hospital space with the corresponding requirements concerning the sizes of offices and corridors (wards of hospitals, offices of doctors, operating rooms, etc.):

- volumes of premises of other spaces with corresponding requirements concerning their sizes (laboratory, scientific, experimental-production, administrative and economic purpose).

Depending on the spatial solution of the university hospital for the organization of hall spaces it is possible to use both wall and frame structures with flat (beams, trusses, frames and arches) or spatial floor, and the use of multi-span structural elements (shells, folds, cable, spatial-rod structures), that allow obtaining expressive three-dimensional solutions. Other groups of rooms, which are characterized by the presence of small cells of space, can be solved in wall or frame structures (with a step of $6 \times 6,6 \times 9,6 \times 7.5 \mathrm{~m}$ ). As building materials, it is recommended to use brick, precast and monolithic concrete, glass, various types of metals, treated wood. The issue of the choice of sanitary and hygienic, fire and thermal insulation characteristics and indicators when choosing the types of construction and finishing materials.

\subsection{The Masterplan of the University Hospital}

When developing the master plan of the university hospital, it is necessary to provide for the zoning of the territory to the main (for the emergency medical service, for visitors and staff) and auxiliary-economic. The emergency medical care area necessarily provides for the organization of a separate entrance to the territory and auxiliary from other adjacent streets in case of placement in a dense urban development, as well as a specially covered entrance group to the reception, a place for waiting and storage of official vehicles. It is also advisable to arrange a helipad. The visitor area must include a parking lot (possibly underground), a children's playground, a recreation and waiting area, sun protection structures, a ramp at the entrance groups. Mandatory elements of the hospital staff area should include parking (possibly underground) and a recreation area. The economic zone renders a convenient location of auxiliary equipment to keep the area clean and place the garbage storage containers, etc. The design of the master plan requires a modern solution and design of the territory of the medical institution, including the use of landscape methods and approaches to design (various types of landscaping, types of coverage, recreation areas, artificial reservoirs, the introduction of small architectural forms).

\subsection{Aesthetics and Artistic Image of the University Hospital}

When developing a project for a university hospital, in addition to architectural and urban planning, functional planning and spatial tasks, the issue of the aesthetic and psychological spectrum of human perception of a medical institution deserves separate consideration [37]. Nowadays, there are proven results on the healing properties of architectural space - a person recovers faster in the most comfortable, psychologically soothing, close to the natural environment. Therefore, when designing a university hospital, it is extremely important to move away from the stereotypical notion of traditional-typical exterior and interior appearance of medical institutions, use of advanced foreign experience in designing health care buildings and implement modern global trends in the design of medical institutions. Architectural and planning space help heal at least psychologically [15, 22]. In this aspect, the global trends in the design of health care facilities include the following: the close connection of the internal and external environment of the medical institution, their maximum proximity to the natural environment and active implementation of landscape design, artificial reservoirs, use of natural finishing materials, significant area glazing of premises, etc. The artistic image of the university hospital should evoke in the sick person a feeling of trust, reliability, elation, calmness, desire to visit the institution in the future in case of need and necessity. Creating an expressive, artistic and emotional image of the university hospital will help to 
individualize the design solution and increase the aesthetic and intellectual aspects of design.

\subsection{The Recommended Functional Scheme and Groups of University Hospital Premises}

There are no two identical university hospitals in the world currently as far as there are always regional needs, opportunities and limitations. Therefore, in a generalized form, the activities of the university hospital are proposed to be considered in terms of the following functional groups: medical; laboratory diagnostic; medical-consultative; educational; research; experimental and production; range of auxiliary functions (hotel, catering, etc.). This list of functional components is incomplete and will certainly be expanded and supplemented in the future. This is due to the constant development of medicine, its methods and medical and diagnostic equipment. In our opinion, one of the key functional areas of a university hospital should be the experimental and scientific function. In this sense, it is the university hospital that has the full potential and capabilities. Having discussed all the main issues of the article, we can form the final part of the research.

\subsection{The Hospital Area Effects the Land Use}

The study of the issue of the land use of the hospital territory is perspective. This research topic unites many aspects. The cores of them are: the ownership of a land plot (private, state, municipal, lease, etc.), it's purpose of use, restrictions on development (number of stories of buildings, etc.). In addition to the mentioned above facts the issue is related to the form of ownership and financing of hospitals and other medical buildings. This research topic lies inbetween the spheres of interest of those countries that are reforming their health sectors systems. For example, during the Soviet period there was an exclusively state form of management and ownership of the health care system in Ukraine. Just recently the private and communal medical centers and hospitals are emerging. In this perspective, the issue of land use is really important, since it directly affects the scale of the medical complex, the financial investments, and the development and quality of improvement of the hospital area. Thus, the issue of land use can be both a constraining and a stimulating factor in the design process of the university hospital complexes.

\subsection{The Objective Criteria Comparison Based on the All Examples}

To conclude, it is advisable to compare all the examples considered in this article. This might make it possible one to identify and compare the main indicators and criteria of individual projects of the university hospitals, which are presented in Table 8 . The obtained data may be useful for the perspective architecture design of the university hospital buildings and complexes.

Table 8. The objective criteria comparison based on the all examples

\begin{tabular}{|c|c|c|c|c|c|}
\hline & Total Area & Number of Patients & Number of Beds & Patient Rooms & Operation Hall \\
\hline $\begin{array}{c}\text { The Kyiv City Clinical Hospital } \\
\text { No. 8, Kyiv, Ukraine }\end{array}$ & no data & no data & 870 & & + \\
\hline $\begin{array}{c}\text { The Dnipro City Clinical } \\
\text { Hospital No. 9, Dnipro, } \\
\text { Ukraine }\end{array}$ & no data & 17.000 & no data & & + \\
\hline $\begin{array}{l}\text { The City Clinical Hospital No. } \\
\text { 1, Minsk, Belarus }\end{array}$ & no data & no data & 650 & & + \\
\hline $\begin{array}{l}\text { The National Clinical Hospital, } \\
\text { Barnaul, Russia }\end{array}$ & no data & 35.000 & 1.265 & & + \\
\hline $\begin{array}{c}\text { The University Hospital } \\
\text { Hamburg-Eppendorf, Hamburg, } \\
\text { Germany }\end{array}$ & no data & $\begin{array}{c}95.000 \text { inpatients } \\
\text { and } 335.000 \\
\text { outpatients }\end{array}$ & 1.700 & & + \\
\hline $\begin{array}{l}\text { The University medical } \\
\text { complex, Freiburg, Germany }\end{array}$ & no data & $\begin{array}{c}91.000 \text { inpatients } \\
\text { and } 872.000 \\
\text { outpatients }\end{array}$ & 2.107 & & + \\
\hline $\begin{array}{c}\text { The Johannes Gutenberg } \\
\text { University Medical Centre, } \\
\text { Mainz, Germany }\end{array}$ & no data & $\begin{array}{c}70.000 \text { inpatients } \\
\text { and } 300.000 \\
\text { outpatients }\end{array}$ & 1.500 & & + \\
\hline $\begin{array}{c}\text { The Queen Elizabeth University } \\
\text { Hospital, Glasgow, Scotland }\end{array}$ & $175.000 \mathrm{~m}^{2}$ & no data & 1.677 & 1.109 & + \\
\hline $\begin{array}{l}\text { The University of Montreal } \\
\text { Hospital Centre, Montreal, } \\
\text { Canada }\end{array}$ & $280.000 \mathrm{~m}^{2}$ & $\begin{array}{c}345.000 \text { outpatients, } \\
22.000 \text { inpatients } \\
\text { and } 65.000 \\
\text { emergency }\end{array}$ & 1.259 & $\begin{array}{l}772 \text { and } 39 \\
\text { rooms for } \\
\text { operating }\end{array}$ & + \\
\hline $\begin{array}{c}\text { The Køge University Hospital, } \\
\text { Koge, Denmark }\end{array}$ & $180.000 \mathrm{~m}^{2}$ & 280.000 & no data & no data & + \\
\hline
\end{tabular}




\section{Conclusion}

Today, the university hospital is one of the most promising and effective forms of organization of hospital structures. This is primarily due to the fact that the university hospital is a multifunctional medical institution, which within the territorial boundaries of one complex combines and synthesizes the interaction of a number of related functions: multidisciplinary and specialized medical, educational and training medical profile, research and experimental production, as well as many ancillary services, which together create the conditions for an emergent effect in the work of the hospital. It is possible to design university hospitals both in the new suburban area, free from the surrounding buildings and with a significant potential for landscaping of the medical complex. In this case, it is advisable to design a centralized building of the university hospital with small and medium-sized buildings, which, in case of further need, will allow more freedom to expand the health care facility. In the case when it is decided to create a university hospital in the existing urban environment on the basis of the expansion of an existing hospital or educational medical institution, it is advisable to design a centralized building with a combined volume of high and medium storeys. The article provides a systematization of the existing experience in the construction of clinical and university hospitals, a discussion of the main provisions, features and recommendations. In particular, problems and issues of architectural and planning, structural solutions, the use of building materials, the organization of general plans, the need to introduce aesthetic and artistic solutions in the design of university hospitals are considered. The main conclusion of the article is the understanding that each university hospital is a unique object and cannot be designed as a typical project. In each specific case, it is necessary to conduct a thorough pre-project study regarding the tasks, goals, capabilities of the future hospital, the characteristics of the territory, the living population and the main types of morbidity, etc. Despite the initially large time and financial costs for the design and construction of a university hospital, in our opinion, it is this type of hospital buildings that is progressive and promising. For further research, a number of issues are proposed, including: interconnection and optimal number of floors of various functional blocks, compact placement in an urban environment, the introduction of helipads for the provision and operation of medical air transport, energy-efficient solutions, the use of underground space, landscape and improvement, aesthetics of university hospitals.

It is worth mentioning that since the university medical complexes have transformed into the large buildings (or a group of buildings) they certainly exert a negative impact on the environment, especially on an urban scale. Therefore, while designing the university medical complexes it is necessary to take into account the principles of sustainable development and apply them into an ecological design approach, which is aimed at reducing the negative impact of urbanization processes on the environment.

\section{Acknowledgements}

This research did not receive any specific grant from funding agencies in the public, commercial, or not-for-profit sectors.

The authors are grateful to reviewers for their help and support while preparing the article.

\section{REFERENCES}

[1] D. W. Baker, M. R. Chassin. Holding Providers Accountable for Health Care Outcomes, Annals of Internal Medicine, Vol. 167, No. 6, 418-423. https://doi.org/10.732 6/M17-0691

[2] H. Burstin, S. Agrawal, A. Qaseem. Moving to Measures That Matter and Motivate Change, Annals of internal medicine, Vol. 167, No. 6, 442-443. https://doi.org/10.732 6/M17-1855

[3] I. Bulakh, O. Chala, V. Divak. Dynamics of Architectural and Urban Planning Hospital Systems Evolution, Civil Engineering and Architecture, Vol. 8, No. 4, 586-598. https://doi.org/10.13189/cea.2020.080423

[4] D. G. Yilmaz. Model Cities for Resilience: Climate-led Initiatives, Journal of Contemporary Urban Affairs, Vol. 5, No. 1, 47-58 https://doi.org/10.25034/ijcua.2021.v5n1-4

[5] M. A. Amen, H. A. Nia. The Effect of Centrality Values in Urban Gentrification Development: A Case Study of Erbil City, Civil Engineering and Architecture, Vol. 8, No. 5, 916-928. https://doi.org/10.13189/cea.2020.080519

[6] H. A. Nia, F. Olugbenga. A Quest on the Role of Aesthetics in Enhancing Functionality of Urban Planning, Civil Engineering and Architecture, Vol. 8, No. 5, 873-879. https://doi.org/10.13189/cea.2020.080514

[7] O. K. Akande. Urbanization, Housing Quality and Health: Towards a Redirection for Housing Provision in Nigeria, Journal of Contemporary Urban Affairs, Vol. 5, No. 1, 35-46. https://doi.org/10.25034/ijcua.2021.v5n1-3

[8] R. Rahbarianyazd, H. A. Nia. Aesthetic cognition in architectural education: a methodological approach to develop learning process in design studios, International Journal of Cognitive Research in Science, Engineering and Education, Vol. 7, No. 3, 61-69. https://doi.org/10.5937/IJCRSEE1903061R

[9] U. A. Nassar. Urban Acupuncture in Large Cities: Filtering Framework to Select Sensitive Urban Spots in Riyadh for Effective Urban Renewal, Journal of Contemporary Urban Affairs, Vol. 5, No. 1, 1-18 https://doi.org/10.25034/ijcua. 2021.v5n1-1 
[10] I. Bulakh, L. Kozakova, M. Didichenko, O. Chala. Sustainable futures in the context of architectural design of hospitals, E3S Web of Conferences, Vol. 166. https://doi.org/10.1051/e3sconf/202016608001

[11] H. A. Nia, R. Rahbarianyazd. Aesthetics of Modern Architecture: A Semiological Survey on the Aesthetic Contribution of Modern Architecture, Civil Engineering and Architecture, Vol. 8, No. 2, 66-76. https://doi.org/10.13189/cea.2020.080204

[12] M. Aziz Amen, H. Nia. The dichotomy of society and urban space configuration in producing the semiotic structure of the modernism urban fabric, Semiotica, Vol. 2018 (222), 203-223. https://doi.org/10.1515/sem-2016-0141

[13] C. O. Agayi, Ö. Karakayacı. The Role of Changing Housing Policies in Housing Affordability and Accessibility in Developing Countries: The Case of Kenya, Journal of Contemporary Urban Affairs, Vol. 4, No. 2, 49-58. https://doi.org/10.25034/ijcua.2020.v4n2-5

[14] I. Bulakh, L. Kozakova, M. Didichenko, O. Chala, G. Kovalska. Is the hospital-park future of the sustainable hospital architecture?, E3S Web of Conferences, 280, 04014. https://doi.org/10.1051/e3sconf/202128004014

[15] I. Bulakh, L. Kozakova, M. Didichenko. The innovative trends in architecture and urban planning of health care institutions, International Journal of Innovative Technology and Exploring Engineering, Vol. 9, No. 1, 317-323. https://doi.org/10.35940/ijitee.A4111.119119

[16] I. Bulakh, L. Kozakova, M. Didichenko, O. Chala. Health Care Architectural and Urban Planning Systems in The United States of America and France, International Journal of Innovative Technology and Exploring Engineering, Vol. 9, No. 2, 1622-1627.https://doi.org/10.35940/ijitee.B7377. 129219

[17] A. Yavuz, N. Ataoğlu, H. Acar. The Identification of The City on The Legibility and Wayfinding Concepts: A Case of Trabzon, Journal of Contemporary Urban Affairs, Vol. 4, No. 2, 1-12. https://doi.org/10.25034/ijcua.2020.v4n2-1

[18] I. Bulakh, L. Kozakova, M. Didichenko, O. Chala. Architectural and urban planning system of health care in Germany and the United Kingdom, Space \& Form, Vol. 41, 141-148. https://doi.org/10.21005/pif.2020.41.C-02

[19] I. Bulakh. Artistic and Aesthetic Formation and Evolution of Architectural and Urban Planning Space, Science and Innovation, Vol. 15, No. 5, 47-56. https://doi.org/10.15407/scine15.05.057

[20] I. Bulakh. Common Features of Architectural Design of the Medical Purpose Building, Science \& Technique, Vol. 18, No. 4, 311-318. https://doi.org/10.21122/2227-1031-201918-4-311-318

[21] I. Bulakh. Urban Planning Organization and Development of Children's Medical Institutions in Ukraine, Journal of Regional and City Planning, Vol. 31, No. 1, 82-96. https://doi.org/10.5614/jpwk.2020.31.1.6

[22] I. Bulakh, I. Merylova. Sustainable Hospital Architecture Potential of Underground Spaces, Civil Engineering and Architecture, Vol. 8, No. 5, 1127-1135. https://doi.org/10.13189/cea.2020.080539
[23] A. Balaghi, R. Balaghi, M. Rezaei, F. Shaer, M. Akbari Riyabi. Spatial analysis and urban land use planning emphasising hospital site selection: a case study of Isfahan city, Bulletin of Geography, Socio-economic Series, Vol. 43, No. 43, 71-89. http://doi.org/10.2478/bog-2019-0005

[24] G. Kovalska, I. Merylova, I. Bulakh. Urban improvement of comprehensive schools and out of school educational establishments in Ukraine, International Journal of Innovative Technology and Exploring Engineering, Vol. 8, No. 12, 1765-1770. https://doi.org/10.35940/ijitee.L3229.1 081219

[25] W. Smit, T. Hancock, J. Kumaresen, C. Santos-Burgoa, R. Sánchez-Kobashi Meneses, S. Friel. Toward a research and action agenda on urban planning / design and health equity in cities in low and middle-income countries, Journal of urban health: bulletin of the New York Academy of Medicine, Vol. 88, No. 5, 875-885. https://doi.org/10.1007/s11524-011-9605-2

[26] M. Grant. European Healthy City Network Phase V: patterns emerging for healthy urban planning, Health promotion international, Vol. 30, No. 1, 154-170. https://doi.org/10.1093/heapro/dav033

[27] S. Nakano, A. Washizu. Will smart cities enhance the social capital of residents? The importance of smart neighborhood management, Cities, Vol. 115, 103244. https://doi.org/10.1 016/j.cities.2021.103244

[28] M. Lowe, P. Hooper, H. Jordan, K. Bowen, I. Butterworth, B. Giles-Corti. Evidence-Informed Planning for Healthy Liveable Cities: How Can Policy Frameworks Be Used to Strengthen Research Translation?, Current environmental health reports, Vol. 6, No. 3, 127-136. https://doi.org/10.1007/s40572-019-00236-6

[29] O. Ramirez-Rubio, C. Daher, G. Fanjul, M. Gascon, N. Mueller, L. Pajin, A. Plasencia, D. Rojas-Rueda, M. Thondoo, M. J. Nieuwenhuijsen. Urban health: an example of a "health in all policies" approach in the context of SDGs implementation, Globalization and health, Vol. 15, No. 1, 87. https://doi.org/10.1186/s12992-019-0529-z

[30] M. Reisert, C. Weiller, J. A. Hosp. Displaying the autonomic processing network in humans - a global tractography approach, NeuroImage, Vol. 231, 117852. https://doi.org/10.1016/j.neuroimage.2021.117852

[31] A. Sebastian, K. Rößler, M. Wibral, A. Mobascher, K. Lieb, P. Jung, O. Tüscher. Neural architecture of selective stopping strategies - distinct brain activity patterns are associated with attentional capture but not with outright stopping, Journal of Neuroscience, Vol. 37, No. 40, 1476-17.

https://doi.org/10.1523/JNEUROSCI.1476-17.2017

[32] G. Kovalska, I. Bulakh, M. Didichenko, O. Kozakova, O. Chala. Higher education institutions energy efficient methods of functional planning solution, E3S Web of Conferences, 280, 04013. https://doi.org/10.1051/e3sconf/ 202128004013

[33] H.A. Nia, R. A. Atun, R. Rahbarianyazd. Perception Based Method for Measuring the Aesthetic Quality of the Urban Environment: The Case of Famagusta, Journal of open House international, Vol. 42, No. 2. 11-19. https://doi.org/10.1108/OHI-02-2017-B0003 
[34] H. A. Nia, R. A. Atun. Aesthetic design thinking model for urban environments: A survey based on a review of the literature, Urban Design International, Vol. 21, 195-212. https://doi.org/10.1057/UDI.2015.25

[35] A. Morrow, T. Ford, K. Mangion, T. Kotecha, R. Rakhit, G. Galasko, S. Hoole, A. Davenport, R. Kharbanda, V. Ferreira, M. Shanmuganathan, A. Chiribiri, D. Perera, H. Rahman, J. Arnold, J. Greenwood, M. Fisher, D. Husmeier, N. Hill, X. Luo, N. Williams, L. Miller, J. Dempster, P. Macfarlane, P. Welsh, N. Sattar, A. Whittaker, A. Mc Connachie, S. Padmanabhan, C. Berry. Rationale and design of the Medical Research Council's Precision
Medicine with Zibotentan in Microvascular Angina (PRIZE) trial, American Heart Journal, Vol. 229, 70-80. https://doi.org/10.1016/j.ahj.2020.07.007

[36] M. Nzololo. Towards Hospital Marketing at the Brazzaville University Hospital Center, Open Journal of Business and Management, Vol. 8, 2409-2422. https://doi.org/10.4236/o jbm.2020.86149

[37] S. S. M. Al-Din, H. A. Nia. "Beauty" Based on the Functionality of Smart Skin in Buildings, Open House International, Vol. 42, No. 4, 60-69. https://doi.org/10.110 8/OHI-04-2017-B0008 